\title{
The Problem of Satisfaction with The Results of The Professional Activity of The Employees of The Penal System of The Russian Federation
}

\author{
Yuri Evgenievich Suslov ${ }^{1,2 *}$, Yuri Yuryevich Tishchenko ${ }^{3}$, and Anastasia Andreyevna \\ Samoylova ${ }^{4}$ \\ ${ }^{1}$ Research Institute of the Federal Penitentiary Service of Russia, Department of Investigation of the \\ Russian and Foreign Experience, the History of the Penal System, Comparative Analysis of Penal Law, \\ 125130, Moscow, Russia \\ ${ }^{2}$ Russian State Social University, Department of labor psychology and psychology of special needs, \\ Moscow, Russia \\ ${ }^{3}$ Research Institute of the Federal Penitentiary Service of Russia, Department For The Development of \\ Methodologies For Social, Psychological, Educational And Pedagogical Work With Convicts Of The \\ Center For The Study of Problems of The Criminal Sentences Execution And The Psychological \\ Support of The Professional Activities of The Employees of The Penitentiary System, 125130, \\ Moscow, Russia \\ ${ }^{4}$ Research Institute of The Federal Penitentiary Service of Russia, Department for Research on The \\ Problems of Employment of Convicts and Economic Problems of The Functioning of The Penal \\ System, 125130, Moscow, Russia
}

\begin{abstract}
The article considers the problem of satisfaction with work and results of work on the example of the professional activity of the penal system employees. In this regard, the purpose of the study, reflected in this work, is to analyze the professional activities of the penal system staff of the Russian Federation. The objective was achieved by analyzing scientific sources devoted to the problem of work, professional activity, and satisfaction with their results, as well as the study and comparison of the results of research conducted in the penal system. During the research, such general scientific methods and techniques as analysis, synthesis, comparison, induction, and deduction were applied.

The study draws a parallel between satisfaction with professional choices and satisfaction with one's own life in general, emphasizing the existential nature of the discussed issue. In conclusion, the authors describe the levels of perception of professional activities results by penal system staff. The obtained results can be used for preventive, educational, and corrective measures with penal system staff.
\end{abstract}

\section{Introduction}

The tasks imposed by the society on the penal system of the Russian Federation (hereinafter - PS) stipulate high requirements to the professional and personal qualities of

\footnotetext{
*Corresponding author: zimburu@mail.ru
} 
employees. The extreme nature of the service, associated with a real threat to life and health, high physical and mental stress, etc., leads to the fact that the risk of developing disruptive forms of behavior among employees is quite high. Effective preventive and corrective work based on modern research can counteract this process.

The consequence of the multifaceted professional activity of PS employees is that there are many problematic issues, which are also in dynamics, i.e. changing, and these changes should be anticipated and considered for the organization of activities. Such problems as professional selection, stress resistance, prevention of destructive manifestations, professional and personal development, emotional burnout, professional deformation, etc. always remain relevant in PS.

However, another problem remains, which, we believe, is not sufficiently considered in contemporary research works. This is a problem of satisfaction with the professional work results of PS staff. This problem is part of the more general problem of job satisfaction.

Thus, we assume that satisfaction with the results of one's professional work lies at the core of work efficiency and contributes to reducing the development of disruptive processes of the employee's personality. As a result, the purpose of our research was to study the satisfaction with the results of professional work by the employees of PS in the Russian Federation.

The study included solutions to several problems. First, it was necessary to analyze the available scientific sources revealing the problems of satisfaction with work, professional activity, and their results by employees. Second, it was necessary to analyze the available studies concerning the specifics of the professional activity of the employees of the penal system, as they directly affect the employee's attitude towards the chosen profession in general. The data obtained will allow achieving the third objective - to determine the specifics of satisfaction of PS employees with their professional work results.

\section{Methods}

The study of the scientific and practical problem of job satisfaction included a theoretical analysis of available scientific sources on this problem. Thus, in the Russian science, such scientists as A.A. Derkach [1], E.F. Zeyer [2], F.N. Ilyasov [3], E.A. Klimov [4], N.V. Kuzmina [5], G.S. Nikiforov [6], O.G. Noskova [7], M.V. Sekach [8], G.V. Sukhodolsky [9], V.A. Tolochek [10], V.D. Shadrikov [11], etc. were among those who addressed the issue of job satisfaction.

It should also be noted that the study of this problem has a long history in scientific space. In Russian and foreign studies, attempts were made to identify those aspects and factors that, or a set of which, have an impact on job satisfaction by the subject of activity. Such factors were the size of wages, working conditions, labor content, the availability of the opportunity to realize themselves, and their professional and personal potential. In the works of Soviet scientists of the $1960 \mathrm{~s}$, for example, there were studies of determining the time of "joyful labor" (the establishment of periods during the working day when a worker gets tired; the determination of the time of work of the subject of activity without tension; the identification of the number of hours during which the worker felt pleasure from the work being done) [12]. Besides the marked factors, the satisfaction of work can be influenced by the material and technical support of work, organization of work, relations in the collective, management style, state of the moral and psychological climate, mode and schedule of work, distance of work from the place of residence, etc. Satisfaction with the results of one's work should be highlighted separately in this list.

The necessity of modern studies of this theme is connected with active changes in social, economic, and world outlook context of time. Trend changes in the system of values, prestige, and importance of this or that sphere of activity, etc., directly affect the employees' perception 
of their profession and themselves in the profession. For PS, this is particularly relevant because, as some scholars have noted, the prestige of service in the penal system is low [13].

Abroad, the issue of professional satisfaction of penitentiary service staff is also relevant. The studies are conducted from different angles, which underlines the multidimensional nature of the problem.

In particular, the traumatic impact of prison conditions on human mental health has been noted $[14,15]$. The researchers establish a correlation between the satisfaction of correctional institution staff and different management approaches [16]. Besides, they note the influence on professional choice, as well as the subsequent assessment of the profession, such facts as sex, age, level of education, correctional institution regime, etc. [17]. In the context of satisfaction with work of correctional institution staff, foreign researchers note the importance of support from the institution's management and colleagues [18], as well as the dependence of satisfaction with the profession and satisfaction with their lives, the presence of which affects the effectiveness of their professional duties [19, 20]. Ignoring various factors of performance that affect job satisfaction leads to negative consequences both for the employees themselves (personal disruption) and for the correctional institution (high employee turnover, understaffing, etc.) [21].

\section{Results}

The theoretical analysis of various scientific sources, as well as their correlation and comparison, allowed us to assert that the satisfaction (or dissatisfaction) of PS staff with their professional choices is ultimately closely related to life satisfaction (dissatisfaction). Wrong career choices lead to frustration, apathy, and disinterest in their professional development and quality job performance. As a result, both the staff member and the service "suffer". It should be noted, however, that a staff member's disappointment in their choice might occur at any of the periods of service. Thus, a staff member may become disillusioned at the beginning of their career when they face a direct need to perform their duties. This can be explained by the mismatch of individual expectations and perceptions of service, the staff member's infantile nature, their unpreparedness to perform their duties, the exercise of choices without regard to their capacities and preferences. Disillusionment may also occur after several years of service. Reasons for such frustration may include the experience of crises related to age, changes in the family (divorce, childbirth, etc.), reassessment of values, changes in beliefs, etc. Habitual activity and lifestyle do not bring satisfaction and positive emotional response.

\section{Discussion}

We see the solution to the problem of satisfaction of a PS employee with their professional performance in several scenarios of their behavior. One of the possible solutions in this situation is to change activities and leave the service. However, with such a solution, PS may suffer losses in competent professionals with important practical experience. Besides, due to subjective and objective reasons (fear of change, lack of jobs in the region, etc.), an employee does not leave the service that does not satisfy them and triggers an emotional burnout mechanism. As a result, the emotional state of the employee is decreased, the efficiency and quality of the work performed will also be reduced, and the probability of conflicts in the service will increase.

There is an alternative way to overcome this problem. It consists in finding a new meaning for the employee. An important part of this work will be to gain satisfaction with the results of their activities. 
The solution to the described problem includes answering the question of what is the result of the PS employee's activity. We assume that the answer to this question should include the levels of understanding of the work result. In other words, we should consider the understanding of work at:

- the employee's personal level;

- the level of the group united by a single line of work (the result of the activities of the education service, psychological service, production services, etc.);

- the PS level;

- the social level.

At the personal level, an employee must have a strong understanding of why they perform their professional activities, why they perform individual actions and operations in their professional life. Frequently, a lack of understanding of these processes at the personal level leads to a negative perception of them, forming a belief that they are useless, and as a result, the whole activity of the employee is useless.

At the group level, the employee must understand the purpose and importance of the professional direction to which they belong. At the same time, this understanding should include an awareness of the role of the service in the system of other PS services. A distorted understanding of the importance and role of one's service in the PS system may lead to an underestimation of the importance of the other services (as a result, the development of interservice conflicts), or to an underestimation of one's service (forming a belief in the futility of one's professional efforts).

At the PS level, an employee must understand what exactly their contribution is to the tasks that PS faces. This creates a sense of belonging to the organization and corporate culture.

The employee must also have a clear understanding of the meaning that PS has in society (public level). Lack of understanding of this meaning naturally leads to the assessment of service at PS only based on external characteristics, which, as mentioned above, are complex and dangerous. Thus, the attractiveness of service in PS for citizens and its prestige is reduced. However, such an assessment is incompetent, based on a misunderstanding of the organization of society.

Thus, working at these levels will allow an employee to broaden the scope of perception and understanding of both their activities and their results, not only at the personal level but also in society.

\section{Conclusion}

The problem of the PS employee satisfaction with their professional activities requires constant in-depth and interdisciplinary research because of its multidimensional nature and the dependence of PS on changing social and political trends in society.

We see the following as perspective areas of the study within the framework of the abovementioned problem: to study satisfaction with the results of employees in different departments and services of PS; to identify the factors contributing to and hindering the development of a sense of satisfaction with the work of employees; to establish a system of personal characteristics of employees and candidates for service, which is most suitable for the successful service in PS; to identify ways to develop a professional culture of the personnel to make them aware of the social role of PS at different levels.

\section{References}

1. A. A. Derkach, V. G. Zazykin, A. K. Markova, Psychology of professional development 
(Izd-vo RAGS, Moscow, 2000)

2. E. F. Zeyer, Psychology of professions (UGPPU, Yekaterinburg, 1997)

3. F. N. Ilyasov, Labor satisfaction (structural analysis, change, connection with production behavior). (Ylym, Ashgabat, 1988)

4. Ye. A. Klimov, The image of the world in diverse professions (MGU, Moscow, 1995)

5. N.V. Kuzmina, Professionalism of the personality of the teacher and master of industrial training (Vyssh. shk., Moscow, 1990)

6. G.S. Nikiforov, N.Ye. Vodopyanova, R.A. Berezovskaya, Ye.S. Starchenkova, Vestnik Sankt-peterburgskogo universiteta 12(4), 42-54 (2015)

7. O.G. Noskova, The history of the psychology of labor in Russia (1917-1957) (Izd-vo MGU, Moscow, 1997)

8. M.F. Sekach, Acmeological foundations of self-regulation of mental stability of military personnel: Ph.D. thesis. (RAGS pri prezidente RF, Moscow, 1999)

9. G.V. Sukhodolskiy, Fundamentals of the psychological theory of activity (Izd-vo Leningr. un-ta, St. Petersburg, 1988)

10. V.A. Tolochek, Modern psychology of labor (Piter, St. Petersburg, 2005)

11. V.D. Shadrikov, Psychology of human activity and ability (Izdatel'skaya korporatsiya "Logos", Moscow, 1996)

12. F.R. Khagur, Vestnik Permskogo universiteta. Filosofiya. Psikhologiya. Sotsiologiya. 1(21), 102-109 (2015)

13. N.A. Samoylik, Teoriya i praktika nauchnykh issledovaniy: psikhologiya, pedagogika, ekonomika i upravleniye 1(5), 99-107 (2019)

14. C. Devaud, L. Wasem, L. Peer, J. Waeny, Archives des Maladies Professionnelles et de l'Environnement 66(2), 131-139 (2005)

15. M. Jordan, Health \& Place 17(5), 1061-1066 (2011)

16. M. D. Reisiga, N. P. Lovrichb, J. Crim. Justice 26(3), 213-226 (1998)

17. E. G. Lambert, J. Liu, S. Jiang, J. Zhang, T.M. Kelley, Int. J. Law, Crime Justice 54, 2133 (2018)

18. E. G. Lambert, K. I. Minor, J. B. Wells, N. L. Hoganc, Soc. Sci. J. 53(1), 22-32 (2016)

19. E. G. Lambert, N. L. Hogan, O. O. Elechi, S. Jiang, J. M. Laux, P. Dupuy, A. Morris, Soc. Sci. J. 46(4), 689-706 (2009)

20. E. G. Lambert, B. Kim, T. Kelley, N. L. Hogand, Soc. Sci. J. 50(2), 195-203 (2013)

21. E. Lambert, E. A. Paoline, Journal of Criminal Justice 38(2), 139-148 (2010) 